\title{
Leukocyte filters: a review of the mechanisms and applications in hemotherapy
}

\author{
Elaine Veloso Rocha Urias ${ }^{1,2,3 *} \odot$, Leandro de Freitas Teles ${ }^{1,2} \odot$, Jamille Fernandes Lula² $\odot$, \\ Caroline Urias Rocha ${ }^{2} \oplus$, Igor Alcântara Pereira ${ }^{\circledR}$, Flavia Naves Givisiez ${ }^{1}$, \\ Agostinho Gonçalves Viana ${ }^{4}$, Tânia de Cássia Moreira Soares ${ }^{2,3} \mathbb{C}^{\circ}$, \\ Silvio Fernando Guimarães Carvalho² ${ }^{2}$
}

\section{INTRODUCTION}

The leukodepletion through specific filters to remove leukocytes from hemocomponents has been applied as a preventive measure of transfusion complications (Figure 1). The whole blood contains about $2 \times 10^{9}-3 \times 10^{9}$ leukocytes; Brazilian legislation determines that leukodepleted components should contain less than $5 \times 10^{6}$, meaning the reduction of $99 \%$ of leukocytes after filtration ${ }^{1,2}$.

Blood banks and industries have sought to reduce transfusion risks. In Brazil, tests for Chagas disease, hepatitis B and C, human T-cell lymphotropic virus (HTLV), human immunodeficiency virus (HIV), syphilis, plasmodium falciparum research in endemic areas of malaria, and cytomegalovirus in specific situations are performed ${ }^{2,3}$. The institution of nucleic acid test for the HIV and hepatitis B and C was introduced to reduce the immune window ${ }^{2}$. Besides infectious risks, immediate reactions to the transfusion may be highlighted, which are currently less controlled ${ }^{2,4-6}$.

Blood components undergoing depletion, irradiation, phenotyping and washing procedures are called special and used in various situations, for example: immunosuppressed patients benefit from irradiated components, polytransfused phenotyped erythrocytes and immunoglobulin A (IGA) deficiency of washed erythrocytes.

This study aims to understand the mechanisms and leukocyte filter applications in hemotherapy and focuses on the use of leukodepleted hemocomponents in Brazil.

\section{METHODS}

This work adopted, as initial criteria, the query to the Index Medicus Medline concerning the use of the keywords "leukocyte filters," "hemotherapy," "filter mechanisms," "hemocomponent filtering," "leukodepletion," and "adverse effects." This selection sought articles in English and Portuguese published during the past 30 years. A careful analysis of 35 articles and related national legislations were performed, and filtered cells' studies and other types of filtration were not considered.

\section{DISCUSSION}

During an allogeneic blood transfusion, the patient receives the donor's leukocytes, and these cells are recognized as strange by the immune system that can result in adverse reactions ${ }^{5,6}$. The main complications related to the presence of leukocytes in the blood are non-hemolytic febrile transfusion reactions (NHFR), alloimmunization to human leukocyte antigens (HLA), platelet refractoriness, graft-versus-host disease (GVHD), and immunomodulatory effects. The transmission of infectious agents such as cytomegalovirus (CMV), HTLV-I/II, and Epstein-Barr virus (EBV) as well as other viruses and parasites may also be associated ${ }^{6}$.

Another undesirable effect of leukocytes is the increased incidence of postoperative infections documented in cardiac surgery; however, factors such as age, previous cardiac surgery, type of surgery, and platelet counts during the preoperative

\footnotetext{
${ }^{1}$ Fundação Centro de Hematologia e Hemoterapia de Minas Gerais, Hemocentro Regional de Montes Claros - Montes Claros (MG), Brazil.

2Universidade Estadual de Montes Claros - Montes Claros (MG), Brazil.

${ }^{3}$ Faculdades Integradas Pitágoras - Montes Claros (MG), Brazil.

${ }^{4}$ Universidade Federal de Minas Gerais - Belo Horizonte (MG), Brazil.

*Corresponding author: elainevru@gmail.com

Conflicts of interest: the authors declare there are no conflicts of interest. Funding: none.

Received on April 13, 2021. Accepted on May 28, 2021.
} 
A

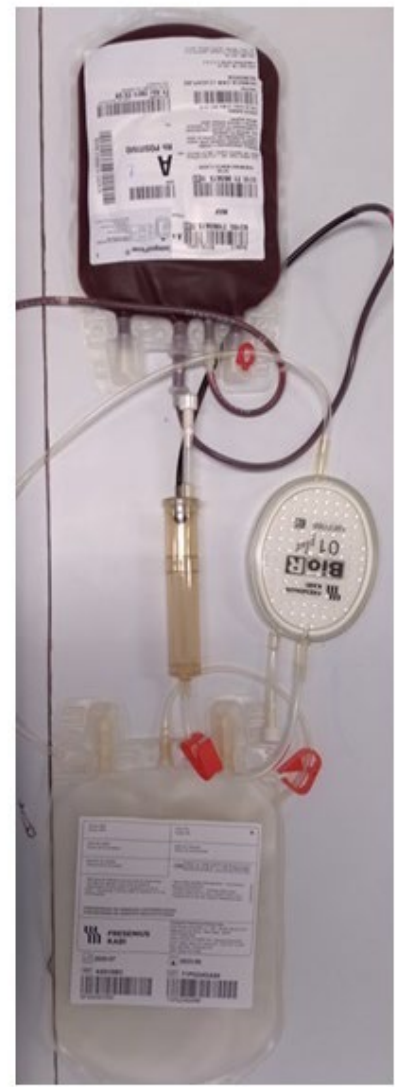

B

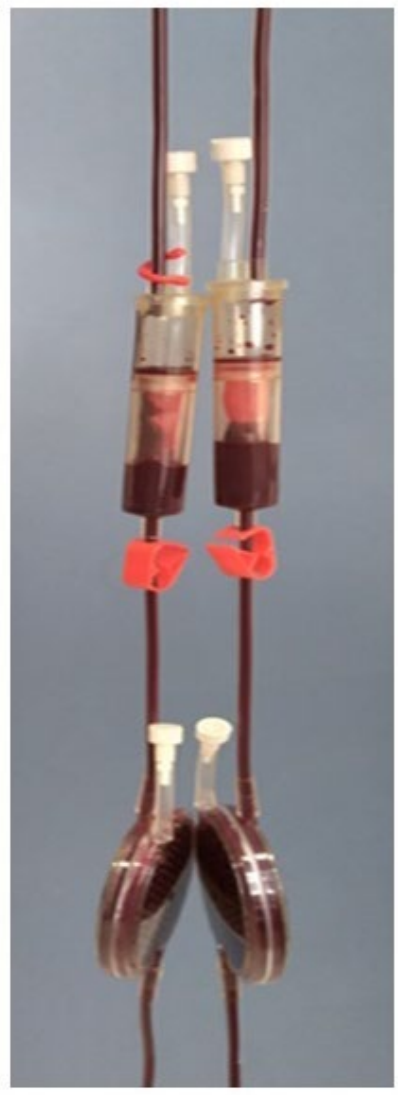

C

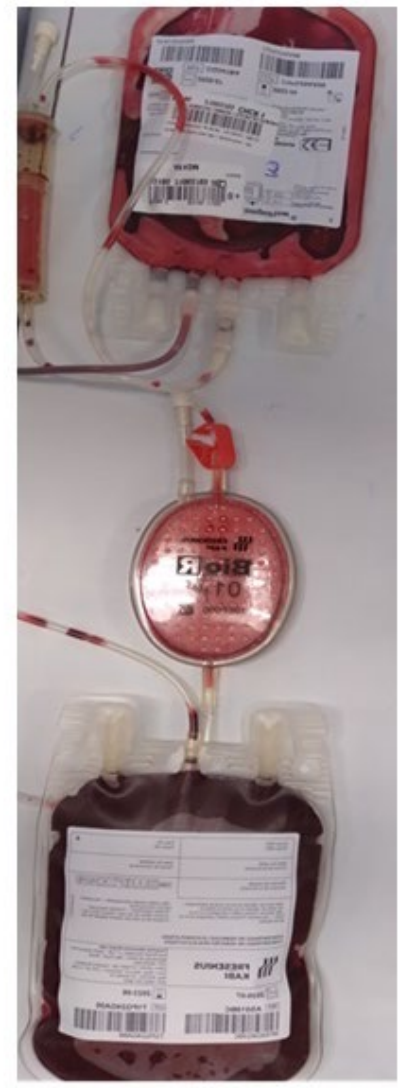

(A) Pre-Filtration; (B) Filtration; (C) Post-Filtration.

Figure 1. Filtration process of the concentrated red blood cell component.

phase related to higher mortality may interfere with the actual analysis of the effect of leukocytes in these patients ${ }^{6,7}$.

In contrast, therapeutic granulocyte transfusion may be beneficial in patients with neutropenia $\left(<500\right.$ neutrophils $\left./ \mathrm{mm}^{3}\right)$ and infection, which is not responsive to therapy.

\section{Leukocyte filters}

The fact that allogeneic leukocytes may promote adverse reactions justifies the reduction of white blood cells $s^{5,6,8}$. The reduction of $100-1,000$ times $(2-3 \log )$ provided by the available leukocyte filters has shown a decrease in the frequency of many adverse reactions ${ }^{5}$.

In order to prevent NHFR, studies demonstrated that the level of necessary reduction is less than $90 \%$, the transmission of some infectious agents $99.9 \%$, platelet alloimmunization $99.9 \%$, and to avoid immunomodulation, this percentage is not known ${ }^{5}$.

The filtration after the development of microaggregate filters removes more than $95 \%$ of the leukocytes, and the loss of red blood cells is less than $10 \%$. The filtration of leukocytes is the most used method to prepare blood poor in leukocytes.
The process is simple, fast, effective, and does not require expensive equipment. Furthermore, it preserves the product's life ${ }^{6,9}$.

Universal leukodepletion (100\% of the blood components produced) has been a transfusion safety policy considered in some countries. Several authors who discuss the costs consider that this analysis is complex due to the difficulty in dimensional long-term morbidity attributed to transfusion. However, they claim that filter indications should be reserved for specific situations because of the competition for resources to other serious public health problems ${ }^{6}$.

The first filters (first generation) developed with the aim to reduce leukocytes present in the blood to be transfused had the capacity to hold approximately $1 \log$ of white blood cells. With the development of a technique "centrifuge, cool, filter," the second generation filters arose promoting retention of about $3 \log$ with verified efficacy to prevent NHFR (10). Currently, third or fourth-generation filters remove more than $99.9-99.99 \%$ ( $>3 \mathrm{log}$ ) of leukocytes originally present in the donated blood. These filters have pores ranging from 5-50 micrometers and are able to meet current hemocomponents' quality standards ${ }^{1,10-12}$. 


\section{Filtering mechanisms}

Filters have small pores that allow the retention of individual cells and increase adsorption capacity. Two main mechanisms are involved as follows: the mechanical entrapment (sieving), dependent on the size of the pores and of deformability of cells, and physical-chemical entrapment or adhesion ${ }^{1,6,9,13}$.

Different factors may be responsible for adherence of white cells to surfaces, such as chemical characteristics, charge, and surface morphology (porosity and roughness). Filters have several layers with different diameter pores, which permit depth filtration. The filter pore size then determines the sieving of particles bigger than $30 \mu \mathrm{m}$ being the adhesion and depth filtration responsible for retaining particles smaller than $1 \mu \mathrm{m}$. Particles of size between 1 and $30 \mu \mathrm{m}$ are retained by the simultaneous action of both processes ${ }^{1,9,14}$.

The filter surface charge can be adjusted by the coating with methacrylate polymers to create a strong positive charge and hence to increase the adhesion surface ${ }^{9,15}$. Some properties of the diverse cells such as diameter, density, deformability, and adhesiveness are essential for the filtration process success ${ }^{1}$.

\section{Moment of filtration}

The blood filtration may be done at the time of processing, post-processing, or at the transfusion moment. However, the prestorage leukodepletion presents the following advantages ${ }^{1,4,6,16}$ :

- Minor accumulation of leukocyte cytokines during storage, which ensures greater efficiency in preventing non-hemolytic transfusion reactions;

- It minimizes HLA alloimmunization risk in multiple transfusion patients, since it removes leukocytes intact during filtration. The filtration during transfusion (bedside) allows the passage of leukocytes fragments and may alloimmunize the receptors;

- It minimizes the risk of lymphotropic virus transmission, which with the degradation of leukocytes and the release of intracellular organisms after 72 hours of storage are no longer retained.

- Besides, it allows the performance of laboratory analysis of quality control.

In Brazil, leukodepletion with bench filters for $\mathrm{CH}$ has often been held up to 48 hours after collection, while for platelets, it is often performed at the bedside. The hemocomponents produced by apheresis already gone through the reduction of leukocytes during processing.

\section{Recommendations on the use of leukocyte filters in Brazil}

The use of leukocyte filters has been recommended for hemoglobinopathies, hereditary hemolytic anemia, history of two or more febrile not hemolytic reactions, congenital immunodeficiency syndrome, candidates for bone marrow transplantation, aplastic anemia, acute myeloid leukemia, severe oncohematological disease till the correct diagnosis and platelet disease patients with the need of a frequent transfusion. For the prevention of CMV, filtration has been indicated in the following conditions: HIV-positive patients with negative serology for CMV; candidate for organ and bone marrow transplantation if the donor and recipient are negative for CMV; intrauterine transfusion, pregnant with nonreactive serology or unknown to CMV, premature newborn, and of low birth weight $(1,200 \mathrm{~g})$; newborns $(\mathrm{NB})$ whose mothers present negative CMV or unknown serology. The effectiveness of leukocyte filters is equivalent to the realization of serology for the prevention of $\mathrm{CMV}^{2}$.

\section{Other leukocyte filter applications}

\section{Virus Transmission Prevention.}

It has been recognized that allogeneic leukocytes from the donor blood are responsible for the virus transmission, such as CMV, human T-lymphotropic virus (HTLV), or EBV ${ }^{14,15,17,18}$. Cytomegalovirus, HTLV-I, and HTLV-II are only transmitted by cellular products' transfusion. If the universal leukoreduction was adopted, these viruses would be removed by filtration, and the blood test to these potential contaminants is not necessary ${ }^{6}$.

Serologic testing for cytomegalovirus in blood banks is recommended for individuals who underwent stem cell and organ transplantation with no positive serology for CMV, newborn children of mothers with CMV negative or unknown serology and who weigh lower than $1,200 \mathrm{~g}$, and intrauterine transfusion, but deleukotized hemocomponents can replace this serol$o g y^{2}$. The serological screening for HTLV has been routinely made for all donors, which makes the use of leukocyte filters deprecated for this purpose ${ }^{2}$.

\section{Bacteria transmission prevention.}

Current studies indicate that a significant percentage of healthy blood donors carry Chlamydia pneumoniae in their blood. The clinical significance of these results is unknown; however, the eradication of these bacteria was verified in leukoreduced units through real-time PCR and immunostaining tests that identified bacteria trapped in the filter mesh ${ }^{19}$. 


\section{Prion transmission prevention}

Prions are infectious proteins related to a variety of progressive and fatal neurodegenerative diseases collectively referred to as transmissible spongiform encephalopathies ${ }^{6,20,21}$. Contamination of leukocytes in the blood raises the risk of abnormal protein prion transmission, probable causative agent of the new variant Creutzfeldt-Jakob disease (CJD) ${ }^{20,21}$.

Leukoreduction reduces up to $42 \%$ of infectivity associated with the infectious prion. Modifications of the specific affinity to prion surface have been developed to increase the filtering efficiency for this end ${ }^{10,20}$. Some countries in Europe and the UK had the universal leukodepletion implemented under this risk $^{11}$. In Brazil, clinical screening eliminates people who were diagnosed with CJD, family history of CJD, significant stay in the UK or Republic of Ireland after 1980, who have received growth hormone or other pituitary origin not recombinant drugs, use of bovine insulin, corneal transplantation and dura mater, and those who have received transfusions of hemocomponents in the UK after $1980^{11}$.

\section{Parasite transmission prevention}

The risk of infection by a parasite associated with transfusion is mainly determined by the following factors: the prevalence of infection, the capacity of survivability of parasites stored in the blood, and the immune competence of the recipient $\mathrm{t}^{22}$. There was an inexplicable decrease in the incidence of malaria transmitted by transfusion in recent years. This fact parallels the increased use of leukocyte filters and the fact that Brazil has clearly defined clinical criteria to prevent transmission, and besides, in endemic areas, tests for plasmodium or plasmodium antigens are mandatory ${ }^{2,22}$.

There are studies that provide evidence that leukocyte reduction filters are effective to reduce the number of parasites in the infected blood such as Trypanosoma cruzi, and this effectiveness depends in part on the concentration of parasites in the artificially infected blood ${ }^{23}$. Fabron Junior evaluated Trypanosoma cruzi retention mechanisms by leukocyte filters. Concentrated samples of red blood cells and platelets were infected with the parasite and then filtered to measure the removal capacity, showing the reduction of approximately $3 \mathrm{log}$. An analysis of the filter fibers demonstrated that T. cruzi parasites were removed by direct adherence to the filter fibers, suggesting a biological mechanism probably mediated by the surface proteins of the parasite $^{23}$. The serology for Chagas' disease research is part of blood banks routine, which is the reason why the use of filters is not necessary for this purpose ${ }^{2}$.

The prevalence of positive serology for visceral leishmaniasis in asymptomatic individuals has been observed in endemic areas $^{25}$. There are few cases in the literature pointing out to transfusion as a likely cause of transmission of this disease ${ }^{25}$. Cardo (2006) demonstrated, in intentionally contaminated blood, the substantial reduction of this parasite after filtration ${ }^{25}$.

\section{TRALI prevention}

Acute lung injury related to transfusion (TRALI) has been associated with transfusions of anti-leukocyte antibodies from the donor which react with alloantigen on the receptors' leukocytes. This potentially fatal complication occurs more frequently in the blood donation of multiparous women. The use of leukocyte filters has been described as a way to mitigate this risk ${ }^{5}$.

\section{CONCLUSION}

It is concluded that in view of the diverse applications of leukocyte filters in hemotherapy, the implantation of universal leukodepletion deserves further studies that determine the cost and benefit of this measure.

\section{ACKNOWLEDGMENT}

We are grateful to the FAPEMIG (Fundação de Amparo à Pesquisa do Estado de Minas Gerais) e Fundação HemominasHemocentro Regional de Montes Claros-MG.

\section{AUTHORS" CONTRIBUTIONS}

EVRU: Conceptualization, Methodology, Writing - original draft. LFT: Formal analysis, Writing - review \& editing. JFL: Formal analysis, Writing - review \& editing. FNG: Formal analysis, Writing - review \& editing. AGV: Formal analysis, Writing - review \& editing. TCMS: Formal analysis, Writing - review \& editing. CUR: Data curation. IAP: Data Curation. SFGC: Formal analysis, Writing - review \& editing

\section{REFERENCES}

1. Bruil A, Beugeling T, Feijen J, van Aken WG. The mechanisms of leukocyte removal by filtration. Transfus Med Rev. 1995;9(2):14566. https://doi.org/10.1016/s0887-7963(05)80053-7
2. Brasil. Portaria $n^{\circ} 158$, de 4 de fevereiro 2016. Redefine o regulamento técnico de procedimentos hemoterápicos. Brasil, 1996. 
3. Brasil. Resolução - RDC n 34, de 11 de junho de 2014. Dispõe sobre as boas práticas no ciclo do sangue. Brasil, 2014.

4. Wang RR, Triulzi DJ, Qu L. Effects of prestorage vs poststorage leukoreduction on the rate of febrile nonhemolytic transfusion reactions to platelets. Am J Clin Pathol. 2012;138(2):255-9. https://doi.org/10.1309/AJCP5H7EKZTGGBKZ

5. Bordin JO, Heddle NM, Blajchman MA. Biologic effects of leukocytes present in transfused cellular blood products. Blood. 1994;84(6):1703-21. PMID: 8080981

6. Dzik S, Aubuchon J, Jeffries L, Kleinman S, Manno C, Murphy $M F$, et al. Leukocyte reduction of blood components: public policy and new technology. Transfus Med Rev. 2000;14(1):3452. https://doi.org/10.1016/s0887-7963(00)80114-5

7. McQuilten ZK, Andrianopoulos N, Van de Watering L, Aubron C, Phillips L, Bellomo R, et al. Introduction of universal prestorage leukodepletion of blood components, and outcomes in transfused cardiac surgery patients. J Thorac Cardiovasc Surg. 2015;150(1):216-22. https://doi.org/10.1016/j. jtcvs.2015.03.015

8. Williamson LM, Stainsby D, Jones H, Love E, Chapman CE, Navarrete C, et al. The impact of universal leukodepletion of the blood supply on hemovigilance reports of posttransfusion purpura and transfusion-associated graft-versus-host disease. Transfusion. 2007;47(8):1455-67. https://doi.org/10.1111/ j.1537-2995.2007.01281.x

9. Sharma RR, Marwaha N. Leukoreduced blood components: advantages and strategies for its implementation in developing countries. Asian J Transfus Sci. 2010;4(1):3-8. https://doi. org/10.4103/0973-6247.59384

10. Gregori L, McCombie N, Palmer D, Birch P, Sowemimo-Coker SO, Giulivi A, et al. Effectiveness of leukoreduction for removal of infectivity of transmissible spongiform encephalopathies from blood. Lancet. 2004;364(9433):529-31. https://doi. org/10.1016/S0140-6736(04)16812-8

11. Wortham ST, Ortolano GA, Wenz B. A brief history of blood filtration: clot screens, microaggregate removal, and leukocyte reduction. Transfus Med Rev. 2003;17(3):216-22. https://doi. org/10.1016/s0887-7963(03)00023-3

12. Dzik S. Leukodepletion blood filters: filter design and mechanisms of leukocyte removal. Transfus Med Rev. 1993;7(2):65-77. https://doi.org/10.1016/s0887-7963(93)70125-x

13. Gérard E, Bessy E, Salvagnini C, Rerat V, Momtaz M, Hénard G. Surface modifications of polypropylene membranes used for blood filtration. Polymer. 2011;52(5):1223-33. https://doi. org/10.1016/j.polymer.2011.01.029

14. Shapiro MJ. To filter blood or universal leukoreduction: what is the answer? Crit Care. 2004;8(Suppl 2):S27-30. https://doi. org/10.1186/cc2453
15. Pietersz RN, van der Meer PF, Seghatchian MJ. Update on leucocyte depletion of blood components by filtration. Transfus Sci. 1998;19(4):321-8. https://doi.org/10.1016/ s0955-3886(98)00056-3

16. Muylle L, Peetermans ME. Effect of prestorage leukocyte removal on the cytokine levels in stored platelet concentrates. Vox Sang. 1994;66(1):14-7. https://doi.org/10.1111/j.1423-0410.1994. tb00270.x

17. Gilbert GL, Hayes K, Hudson IL, James J. Prevention of transfusion-acquired cytomegalovirus infection in infants by blood filtration to remove leucocytes. Neonatal Cytomegalovirus Infection Study Group. Lancet. 1989;1(8649):1228-31. https:// doi.org/10.1016/s0140-6736(89)92330-1

18. Hillyer CD, Emmens RK, Zago-Novaretti M, Berkman EM. Methods for the reduction of transfusion-transmitted cytomegalovirus infection: filtration versus the use of seronegative donor units. Transfusion. 1994;34(10):929-34. https://doi.org/10.1046/j.1537-2995.1994.341095026982.x

19. Ikejima H, Friedman H, Leparc GF, Yamamoto Y. Depletion of resident Chlamydia pneumoniae through leukoreduction by filtration of blood for transfusion. J Clin Microbiol. 2005;43(9):4580-4. https://doi.org/10.1128/JCM.43.9.4580-4584.2005

20. Sowemimo-Coker SO, Pesci S, Andrade F, Kim A, Kascsak RB, Kascsak RJ, et al. Pall leukotrap affinity prion-reduction filter removes exogenous infectious prions and endogenous infectivity from red cell concentrates. Vox Sang. 2006;90(4):265-75. https://doi.org/10.1111/j.1423-0410.2006.00765.x

21. Cervia JS, Sowemimo-Coker SO, Ortolano GA, Wilkins K, Schaffer J, Wortham ST. An overview of prion biology and the role of blood filtration in reducing the risk of transfusiontransmitted variant Creutzfeldt-Jakob disease. Transfus Med Rev. 2006;20(3):190-206. https://doi.org/10.1016/j.tmrv.2006.03.007

22. Cardo $\sqcup$, Salata J, Wilder D. Removal of Plasmodium falciparuminfected red blood cells from whole blood by leukoreduction filters. Transfusion. 2009;49(2):337-46. https://doi.org/10.1111/ j.1537-2995.2008.01974.x

23. Fabron Junior A, Bordin JO, Moraes-Souza H, FreyMuller E, Lages-Silva E. Removal of Trypanosoma cruzi by white cell-reduction filters: an electronmicroscopic study. Rev Soc Bras Med Trop. 1999;32(3):223-7. https://doi.org/10.1590/ s0037-86821999000300001

24. Cardo ᄂ, Salata J, Harman R, Mendez J, Weina PJ. Leukodepletion filters reduce Leishmania in blood products when used at collection or at the bedside. Transfusion. 2006;46(6):896-902. https://doi.org/10.1111/j.1537-2995.2006.00821.x

25. Cardo LJ. Leishmania: risk to the blood supply. Transfusion. 2006;46(9):1641-5. https://doi.org/10.1111/j.15372995.2006.00941.x 